\title{
EDITORIAL
}

\section{Barranquilla, la casa de todos}

$\mathrm{B}$ arranquilla es la primera ciudad de Colombia en el ranking de ciudades del futuro y la séptima del continente según el periódico británico Financial Times en su informe para el periodo 2017-2018 de su Centro de Investigaciones, en el que dan a conocer las regiones, países o ciudades con mejores perspectivas de desarrollo, entre 421 ciudades que fueron evaluadas en el continente.

La Puerta de Oro de Colombia vuelve a recuperar su categoría después de algunos años de confusión, y vuelve con más fuerza, para beneficio de la región y del país. Con el desarrollo de sus puertos marítimos y fluviales, con la mayor autopista que tiene Colombia para comunicar a nueve departamentos y desde ellos al resto del país, con un próximo puerto de aguas profundas y un sistema de planchones ya funcionando, que permite transportar 7.200 toneladas en convoyes que evitan, con cada uno, el tránsito de 255 tractomulas por las carreteras del país y a costos infinitamente inferiores. Con un nuevo puente Pumarejo, que permitirá el desarrollo de 54 kilómetros de importantes puertos a la orilla del río, con acceso directo a los grandes buques. Con un nuevo aeropuerto, para volver a ser la cuna de la aviación de América. Con el mejor sistema de salud de Colombia y su liderazgo en educación desde hace varios años, hoy "la casa de la selección" se convierte también en la "casa" del XIV Congreso Colombiano de Endocrinología Diabetes y Metabolismo y le abre sus puertas y su corazón a todos los endocrinólogos del país, al igual que a todos los profesionales interesados en los temas científicos y académicos que serán tratados en este magno evento de la endocrinología nacional.

En el Centro de Eventos y Convenciones Puerta de Oro como escenario ideal para desarrollar el ambicioso programa científico del Congreso, cuyo tema central será el de debatir acerca de los resultados de los más importantes estudios de investigación en el área de diabetes, dislipidemias, factores de riesgo cardiovascular, osteoporosis, tiroides, ablación de nódulos tiroideos benignos con radiofrecuencia, enfoque endocrinológico del paciente transgénero, manejo de la disfunción eréctil y muchos más, así como la forma de llevar a la práctica diaria en la consulta médica todos esos conocimientos para beneficio directo de los pacientes.

Dieciocho conferencistas internacionales del más alto nivel científico y académico serán los encargados de recorrer la amplia variedad de temas para deleite y provecho de los asistentes y más de ochenta endocrinólogos de todo el país, quienes complementarán con sus experiencias y conocimientos cada una de las jornadas, desde su inicio el 25 de mayo 2017, con tres cursos precongreso hasta su finalización el 28 de mayo con el cierre del congreso en ceremonia oficial.

Con más de 2.500 asistentes al congreso y una programación científica y académica de lujo, con invitados internacionales y nacionales del más alto nivel, el XIV Congreso de Endocrinología, Diabetes y Metabolismo de la Asociación Colombiana de Endocrinología, Diabetes y Metabolismo tendrá en el Centro de Eventos y Convenciones Puerta de Oro y en Barranquilla con su río y su mar de fondo, el mejor escenario para un evento de esta categoría, para disfrute y goce de todos los participantes locales, nacionales y extranjeros, a quienes les damos la bienvenida y les deseamos lo mejor de lo mejor.

Bienvenidos al 14 Congreso Colombiano de Endocrinología, Diabetes y Metabolismo.

\section{Bienvenidos a Barranquilla!}

\section{Carlos Cure Cure, MD}

Presidente del 14 Congreso Colombiano de Endocrinología, Diabetes y Metabolismo 